\author{
스트레스해소법에 따른 한부모가정 부모의 스트레스와 \\ 생활만족도와의 관계 연구 \\ - 중부권 소도시를 중심으로 - \\ 오 승 하*, 조 성 제**
}

\title{
A Research on Relationships between Stress Level of Parents in Single Parent Families and Life Satisfaction in accordance with Stress Removing Methods
}

- Centering on Small Towns in Midsection Sphere -

$$
\text { Seung-ha Oh*, Sung-Je Cho** }
$$

요 약 본 연구는 스트레스해소법에 따른 한부모가정 부모의 스트레스와 생활만족도와의 관계를 파악하고자 한다. 연구대상은 2013년 3월1일부터 7월31일까지 중부권 소도시를 중심으로 한부모가정 부모 260명을 대상으로 설문조사 를 실시하였다. 자료분석은 빈도분석, 요인분석, t-test, 일원변량분석, 상관분석, 회귀분석을 실시하였으며, 실증분석 은 유의수준 $5 \%$ 에서 검증하였다. 연구결과 스트레스는 경제, 신체, 사회 및 일상, 가족, 심리요인 순으로 높게 나타났 고, 스트레스요인의 해소법과 조절효과에 따른 해소정도가 생활만족도에 유의미한 영향을 나타냈다. 그리고 하위요인 은 재정, 정서, 인지적 순으로 유의미하게 나타났다. 연구의 시사점은 생활만족도 증진에 스트레스해소법이 유의미함 으로, 한부모가정 부모에 대한 기초적인 지원정책수립과 프로그램개발의 자료가 될 것으로 사료된다.

주요어 : 한부모, 가정, 스트레스, 해소법, 생활만족도

ABSTRACT This research aims to identify relationships between stress level of parents in single parent families and life satisfaction in accordance with methods of getting rid of stress. Subject of the research were 260 parents in single parent families, centering on small towns in midsection sphere based on answers to questionnaire executed from March 1, 2013 to July 31, 2013. Collected data were analyzed by executing frequency analysis, factor analysis, t-test, one-way ANOVA, correlation analysis, regression analysis, etc. and an empirical verification was performed at $5 \%$ of significance level. From the result of the research, stress level appeared according to factors in a sequence of economic power, physical strength, social relation, family, mentality, etc. and significant influence to life satisfaction was found depending on factors such as stress removing methods and controlling effect. And minor factors were shown in a sequence of finance, emotion and acknowledgement. Suggestive points of the research are thought to be significance of stress removing method to the enhancement of life satisfaction, which will be a good material for the establishment of fundamental supporting plans and development of programs for single parent families.

Key Words : single parent, family, stress, removing method, life satisfaction

* Corresponding Author : Department of Education at Dongbang Graduate University (sunga6996@naver.com)

** Department of Education at Dongbang Graduate University

Received : January 05, 2014 Revised : January 20, 2014

Accepted : January 29, 2014 


\section{I. 서 론}

\section{1 연구의 필요성}

최근 우리나라의 가족형태는 산업화와 경제발 전 및 도시화가 급속히 이루어지면서 가족제도 에서도 과거 혈연중심의 대가족 체계에서 벗어 나 부부와 자녀가 중심이 되는 핵가족구조로 변화하고 있다. 가족구조의 변화에 대하여 도미 향[1]은 사회의 불안정과 각종 산업재해 및 교통 사고로 인한 가족구성원의 상실, 이혼, 사별, 별 거 등으로 가족의 형태가 다양해지고 있으며, 특 히, 배우자와 이혼하는 비율이 증가하면서 한부 모 가족이 증가하고 있는 것이 현실이라고 하였 다. 그리고 황은숙[2]은 한부모가정 부모는 정서 적으로 상실감, 실패감, 불안감, 좌절감, 분노감, 우울감을 느끼며, 경제적 고충 속에서 자녀를 양 육하고, 이혼, 사별 등으로 변화된 가족환경체계 에 적응하지 못해 어려움을 겪고 있다고 한다. 이런 한부모가정은 한쪽 부모와 자녀로 구성된 가정을 의미하며, 이전에는 편부모가정으로 불리 었으나 편(偏)이 반, 절반, 한쪽이란 의미를 담고 있어 부정적으로 작용한다는 지적에 따라서 한 부모가정이란 용어로 순화하여 사용하기에 이르 고 있다[3].

이처럼 가족체계의 변화에 따른 사회구조에서 는 그들이 편안하게 생활할 수 있도록 환경이 미처 조성되어 있지 않고 있으며, 부정적인 이미 지로 다가오고 있는 것이 현실이다. 또한, 아직 은 우리나라의 사회 환경, 경제여건, 자녀양육, 정부의 지원정책 등에서 자유롭지 못하다. 이는 곧 다양한 스트레스 증가와 생활만족도 저하요 인이 되고 있는 것이다.

최근 한부모와 관련된 나라지표와 통계청 인 구주택 총 조사의 장래가구 추계를 살펴보면 다 음과 같다. 한부모의 가구 수는 2005년 1,370천 가구에서 2010년 1,594천 가구, 2011년 1,639가구 로 증가하고 있으며, 전체 가구에서 한부모가구 가 차지하는 비율은 ' 05 년 $8.6 \%$ 에서 ' 10 년 $9.2 \%$, '11년 9.3\%로 증가하고 있다. 또한, 한부모가구
의 형성 원인 중 사별이 $29.7 \%$, 이혼 $32.8 \%$, 미 혼모와 미혼부가 $11.6 \%$ 로 사별 외의 요인으로 한부모가정이 형성되는 비율이 점차 높아지고 있음을 확인 할 수 있다[4]. 이는 곧 다양한 우 리가정의 평등한 가족문화를 저해하는 다양한 사회적 문제의 발생과 스트레스로 작용하고 있 는 것이다.

지금 이 순간에도 한부모의 스트레스는 일상 생활 속에서 여러 가지 문제로 인하여 어려움에 직면하게 되고 제대로 적응하지 못하면 불안이 나 짜증을 내기도 하고 건강을 해치기도 한다. 이러한 과정에서 스트레스를 느끼고 있는 것이 다[5]. 또한, 정부의 한부모가정 지원정책과 관심 은 그들이 스트레스로부터 조금이나마 해소될 수 있는 요인으로 볼 수 있다. 그러나 수혜조 건도 현실성이 없으며, 복지내용도 충분하지 않 아 생활안정과 만족도의 증진에 기여하는 데는 많은 사회적 어려움과 문제점이 있다. 이러한 문 제점을 해결하기 위하여 한부모 스트레스에 대 한 연구가 시작 되었다 $[6,7,8,9,10]$. 한부모 스트 레스에 대한 연구는 스트레스와 삶의 질에 미치 는 영향으로 분류할 수 있다.

스트레스 연구에서 호유연[6]과 남희수[7]는 한부모 가정에서 스트레스에 영향을 미치는 요 인을 분석하였다. 그 결과는 사회적 지지가 양육 스트레스를 감소시키는데 긍정적인 역할을 하는 것으로 나타났다. 그리고 저소득 모자가정 스트 레스가 어떻게 직-간접적으로 작용하는지를 분 석하였다. 이 연구에서는 안정된 생활유지 및 경 제생활 보장이며, 자활과 자립에 의한 빈곤탈출 강화 및 저소득층의 다양한 욕구를 반영한 시책 추진이라고 하였다. 그 이후 김오남[8]은 편모와 그 청소년 자녀를 대상으로 가족스트레스와 심 리복지의 일반적 경향과 편모와 자녀간의 차이 및 상관을 분석하였다. 이 연구에서는 심리복지 증진을 위한 가족자원의 중요성을 올바로 인식 하고 스트레스를 감소시킬 수 있는 방안의 모색 과 사회교육기관에서 교육과 훈련, 정보전달의 필요성을 시사하고 있다. 
삶의 질에 미치는 영향에 대한 연구에서는 김은영[9]은 여성 한부모가족과 남성 한부모 가 족간의 특성을 살펴보고 그 차이를 비교함과 더 불어 한부모가족 안에 포함된 저소득 가구를 추 려내어 법정 저소득 한부모가족과 일반한부모 가족을 비교 연구하였다. 그 결과 저소득 한부모 가정이 경제적 심각성이 매우 높은 것으로 나타 났다. 그 이후 김미숙[10]은 한부모가족 여성의 일과 가정 양립에 따른 환경적 및 심리사회적 요인이 그들의 삶의 질에 미치는 영향과 정책 방안을 연구 하였다. 그 결과 건강상태가 좋을수 록, 자녀수가 적을수록, 사회 환경이 좋을수록 그리고 일과 가정의 갈등이 적을수록, 일과 가정 의 양립이 지향 일수록 삶의 질이 높은 것으로 나타났으며, 일과 가정의 양립이 유지될 수 있도 록 다양한 건강프로그램을 실시하여야 한다고 주장하고 있다.

기존 선행연구들의 문제점은 한부모가족 각 구성원을 대상으로 단편적 주제의 연구를 진행 하였다. 그러나 한부모를 대상으로 한 스트레스 와 해소법 및 개선을 통한 생활만족도 증진을 위한 연구는 없었다. 그 이유는 한부모들이 사회 적 인식과 무시하는 편견 사회적 환경으로부터 자유롭게 나서지 못하고 자신을 숨기고자하는 것도 한 요인으로 작용한다고 볼 수 있다.

본 연구의 필요성은 스트레스해소법에 따른 한부모가정 부모의 스트레스와 생활만족도와의 관계에 관한 상관성 연구가 요구된다.

그래서 본 연구의 목적은 한부모가정 부모를 대상으로 인구사회학적 특성, 일반적인 사항, 사 회 및 일상생활, 가족, 경제, 심리, 신체적 스트 레스의 경향을 살펴보고, 그 다음으로 스트레스 해소법을 변수로 이용하여 연구하고자 한다. 연 구의 내용은 스트레스부터 건강한 생활만족도를 향상시키는데, 어느 정도 상관관계가 형성되고, 유의한 영향을 미치고 있는지를 파악하고자 한 다.

\section{2 연구 문제}

연구의 구체적인 문제는 다음과 같다.

첫째. 인구사회학적 특성요인은 어떠한가?

둘째. 한부모가정 부모의 스트레스는 어떠한가?

셋째, 한부모가정 부모의 스트레스해소법에 따른 생활만족도는 어떠한가?

넷째. 한부모가정 부모의 스트레스와 생활만족도 하위요인과의 관계는 어떠한가?

\section{II. 연구방법}

\section{1 연구대상 및 설문방법}

\subsection{1 연구대상}

연구대상자는 중부권에 위치하고, 생활여건 및 생활수준 그리고 문화여건 등이 유사한 소도 시를 중심으로 연구지역을 한정하였다. 이 지역 에서 한부모가정을 이루며, 자녀를 부양하고 있 는 부모를 연구대상으로 하였다. 즉, 남자 87명 여자 173명 총 260명을 표집 하여, 2013년 3월1 일부터 7월31일까지 설문조사를 실시하였다.

\subsection{2 설문방법}

설문조사는 연구대상자에게 설문조사를 실시 하기 전에 본 설문조사의 취지 및 질문지 작성 방법에 대하여 충분히 설명한 후 개별적 자기기 입법으로 실시하였다. 점수부여 방식은 리커트척 도의 5점 척도로서 스트레스 그리고 스트레스해 소법과 생활만족도 증진요인으로 "전혀그렇지않 다”(1점), “그렇지않다”(2점), “보통이다”(3점), “그렇다"(4점), “매우그렇다"(5점)로 구분하였다. 점수가 높을수록 스트레스해소법과 생활만족도 향상에 대한 유의한 태도가 긍정적이며, 점수가 낮을수록 스트레스해소법과 생활만족도에 향상 에 대한 유의한 태도가 부정적임을 의미한다. 
2.2 연구설계와 가설

\subsection{1 연구설계}

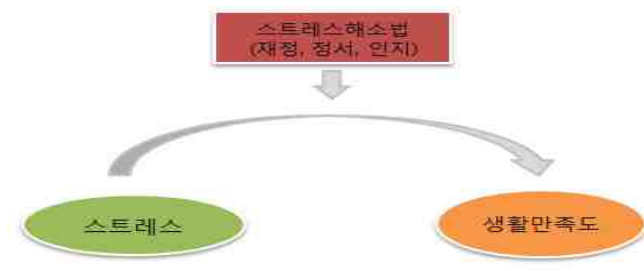

그림 1. 연구설계

Fig 1. Study Design

\subsection{2 연구가설}

연구가설은 한부모가정 부모의 스트레스가 스트레스해소법에 따라 영향을 받을 것이다. 또 한, 스트레스해소법의 조절효과에 따라 생활만족 도가 다르게 나타날 것이다.

\section{3 연구도구}

\subsection{1 인구사회학적 특성요인}

조사도구는 사회 재적응 평가척도[11]를 기 준으로 김오남[8] 문항을 수정·보완하여 실시하 였으며, 인구사회학적 변수로는 성별, 자녀, 연 령, 한부모가 된 사유, 홀로된 기간, 종교, 수입 원 등을 측정하였다. 자녀는 취학전, 초중고, 대 학생, 직장인군으로 하였고, 연령은 20대, 30 대, 40 대, 50 대 이상으로 구분하여 실시하였다. 종교 는 불교, 기독교, 천주교, 원불교, 없다 로 구분 하였으며, 한부모가 된 사유는 미혼모·부, 이혼, 사별, 별거, 가출 등으로 분류 하였다.

\subsection{2 한부모 스트레스 특성요인}

조사도구는 사회 재적응 평가척도[11]를 기 준으로 김오남[8] 문항을 수정·보완하여 실시하 였으며, 한부모가정 부모의 스트레스에 관하여 사회 및 일상생활에 대한 스트레스 11 문항, 가족 에 대한 스트레스 7 문항, 경제와 심리에 대한 스 트레스는 각각 9 문항, 신체적 스트레스는 8 문항 으로 개발 구성하여 답변에 응답하도록 하였다.

\subsection{3 한부모 스트레스해소법 특성요인}

조사도구는 남희수[7] 문항을 기본으로 수정. 보완하였다. 스트레스해소법은 가족관계, 자기개 발, 여가활동, 상담 및 종교단체, 성적욕구, 음주 와 흡연유무 등을 9 문항으로 구분하여 해소법 내용을 설문조사를 실시하였다.

\subsection{4 한부모 생활만족도 특성요인}

조사도구는 사회 재적응 평가척도[11]를 기 준으로 재정적, 정서적, 인지적 요인으로 분류하 였다. 한부모의 생활만족도 향상에 영향을 미치 고 있다고 사료되는 내용을 개발하여 9개 답변 항목에 응답하도록 하였다.

\subsection{5 자료 분석방법}

자료 분석은 모두 유의수준 $5 \%$ 에서 검증하 였으며, SPSSWIN 18.0 프로그램을 사용하여 분 석하였다. 인구학적 특성을 알아보기 위하여 빈 도분석, 생활만족도에 대한 문항들의 타당도 검 증을 위하여 요인분석을 실시하였다. 스트레스와 스트레스해소정도, 생활만족도에 대한 각 문항의 신뢰도는 Cronbach's $a$ 의 계수로 판단하였다. 인구사회학적 특성에 따른 생활만족도의 차이를 알아보기 위하여 t-test와 일원변량분석을 실시 하였으며, 다중범위 검정을 통하여 $\mathrm{p}<.05$ 에서 유 의한 차이를 검정하였다. 스트레스가 생활만족도 에 미치는 영향을 알아보기 위하여 상관분석과 다중회귀분석을 실시하였고, 조절효과를 검증하 기 위하여 위계적회귀분석을 실시하였다.

\subsection{6 생활만족도의 요인분석}

한부모가정 부모의 생활만족도의 요인분석을 실시한 결과는 Table 1.과 같다.

한부모가정 부모의 생활만족도에 대한 타당 도 검증을 위해서 주성분분석방법과 직교회전방 법인 VARIMAX를 사용하여 요인분석을 실시하 였다. 본 연구에서는 $\mathrm{KMO}$ 값이 0.759 로 적당하 므로 변수 쌍들의 상관관계가 다른 변수에 의해 
표 1. 생활만족도의 요인분석

Table 1. Factor analysis of life satisfaction

\begin{tabular}{|c|c|c|c|c|}
\hline & \multirow{2}{*}{ Division } & \multicolumn{3}{|c|}{ Factors } \\
\hline & & 1 & 2 & 3 \\
\hline \multirow{4}{*}{ Financial } & Retirement preparation. & .802 & & \\
\hline & $\begin{array}{l}\text { Independence condition and } \\
\text { will. }\end{array}$ & .781 & & \\
\hline & Daily life and the economy. & .764 & & \\
\hline & Leisure Activities. & .705 & & \\
\hline \multirow{3}{*}{ Emotional } & There is no prejudice. & & .756 & \\
\hline & $\begin{array}{c}\text { Opposite sex and sexual } \\
\text { desire. }\end{array}$ & & .697 & \\
\hline & Peace of mind. & & .515 & \\
\hline \multirow{4}{*}{ Cognitive } & Get help. & & & .873 \\
\hline & Government support policy. & & & .780 \\
\hline & Eigenvalues & 2.701 & 1.565 & 1.506 \\
\hline & Bunsanyul & 30.012 & 17.394 & 16.736 \\
\hline \multicolumn{2}{|c|}{ Cumulative bunsanyul } & 30.012 & 47.406 & 64.142 \\
\hline
\end{tabular}

잘 설명되는 것으로 판단할 수 있다. 또한, 요인 분석의 적합성 여부를 나타내는 Bartlett의 구형 성 검정치는 근사 카이제곱값이 639.142로 유의 수준이 .000으로 나타나 요인분석 사용이 적합하 다는 것을 알 수 있다.

요인을 추출하기 위한 방법으로는 각 요인이 기존변수의 정보를 어느 정도 설명하는지를 나타 내는 고유값을 이용하여, 고유값이 1.0 이상인 요 인에 한하며 요인적재량이 0.5 이상인 항목들을 기 준으로 설정하여 요인수를 3 개로 결정하였다. 그 결과 요인 1은 고유값이 2.701, 설명비가 $30.01 \%$ 로 나타나 재정적 요인을, 요인 2 는 고유값이 1.565 , 설명비가 $17.39 \%$ 로 나타나 정서적 요인을, 요인 3은 고유값이 1.506 , 설명비가 $16.73 \%$ 로 나 타나 인지적 요인을 설명해 주고 있다.

\section{III. 연구결과}

\section{1 인구사회학적 특성요인}

한부모가정 부모의 인구사회학적 특성요인을 살펴본 연구과는 다음과 같다.

성별은 남자는 $33.5 \%$, '여자는 $66.5 \%$ 이었고, 현재 연령은 " 40 대, 50대 이상, 30 대, 20 대 순이었 다. 한부모가 된 시기는 30 대가 가장 많았으며,
한부모가 된 사유로는 이혼이 가장 많았다. 그리 고 한부모 기간은 2-5년 미만이 가장 높게 아타 났다. 종교는 없다는 응답자가 가장 많았고, 교육 정도는 고졸이 대부분이었다. 자녀수는 2 명이 가 장 많았으며, 자녀의 형태는 남매, 형제와 자매, 외동아들, 외동딸 순이었다. 가장 어린 자녀의 상 태는 초,중,고생이 절반이었고, 주 수입원은 본인 이 대부분이었다. 정신적인 도움을 가장 많이 받 는 곳으로는 친구로 나타났고, 월수입은 150-200 만원 미만이 가장 많았다. 정부의 정책적 지원에 대해 지원을 받고 있지 않다가 가장 많았고, 가장 필요한 정책적 지원으로는 자녀보육 및 교육비 지원확대가 가장 많았다. 거주지의 소유형태는 자 가가 가장 많았고, 음주를 하는 응답자는 $63.1 \%$, 흡연을 하는 응답자는 $31.5 \%$ 이었다. 직업은 자영 업이 가장 많았으며, 직장 선택 시 가장 중요한 조건사항으로는 급여가 가장 많았다. 전배우자와 의 관계는 관계가 단절되어 있다가 가장 많았으 며, 스트레스를 받고 있는 것으로 나타났다.

\section{2 한부모 스트레스 특성요인}

한부모가정 부모의 스트레스와 스트레스해소 정도, 생활만족도의 평균과 표준편차를 살펴본 결과는 Table 2.와 같다.

표 2. 스트레스와 정도분석

Table 2. Analysis of stressors and the degree

\begin{tabular}{cccc}
\hline Division & Sub-factors & Mean & SD \\
\hline \multirow{4}{*}{ Stress } & Community and & 2.87 & .67 \\
& everyday life & & \\
& Family & 2.87 & .71 \\
& Economic & 3.24 & .83 \\
& Psychological & 2.81 & .65 \\
& Physical & 3.02 & .73 \\
\hline \multicolumn{2}{c}{ Degree of stress } & 2.57 & .53 \\
Life & Financial & 2.75 & .75 \\
Satisfactio & Emotional & 2.53 & .61 \\
& Cognitive & 2.13 & .72 \\
\hline \multicolumn{2}{c}{ Life Satisfaction } & 2.54 & .53 \\
\hline
\end{tabular}


한부모가정 부모의 스트레스에 대하여 사회 및 일상생활, 가족, 경제적, 심리적, 신체적으로 분류하여 연구를 하였다. 그 결과 경제적 스트레 스, 신체적 스트레스, 사회 및 일상생활 스트레 스, 가족 스트레스, 심리적 스트레스 순으로 스 트레스가 높게 나타났다. 스트레스 해소정도의 평균은 2.57이었다. 생활만족도의 평균은 2.54로, 재정적요인, 정서적요인, 인지적요인 순으로 생 활만족도가 높았다.

\section{3 한부모 스트레스해소법 특성요인}

한부모가정 부모의 스트레스가 생활만족도에 영향을 미칠 때 스트레스 해소정도의 조절효과 를 살펴본 결과는 Table 3.과 같다.

표 3. 스트레스해소법의 조절효과

Table 3. Moderating Effects of Stress

\begin{tabular}{|c|c|c|c|}
\hline \multirow{3}{*}{ Division } & \multicolumn{3}{|c|}{$\begin{array}{c}\text { Dependent variable } \\
: \text { Life Satisfaction }\end{array}$} \\
\hline & 1Step & 2Step & 3Step \\
\hline & B $\beta$ & B $\beta$ & B $\beta$ \\
\hline (Constant) & 4.126 & 3.050 & 2.998 \\
\hline $\begin{array}{c}\text { Community and everyday } \\
\text { life }\end{array}$ & $-.044-.056$ & $-.096-.121$ & $-.110-.140$ \\
\hline Family & $-.044-.058$ & $-.004-.005$ & $.005 \quad .007$ \\
\hline Economic & $-.211^{-.331}$ & $-.160^{-.250}$ & $-.174^{-.272}$ \\
\hline Psychological & $-.118-.144$ & $-.108-.131$ & $-.079-.097$ \\
\hline Physical & $-.106_{*}^{-.145}$ & $-.112_{*}^{-.153}$ & $-.109^{-.149}$ \\
\hline Degree of stress & & $.364 .363^{* *}$ & $.372^{.371^{* *}}$ \\
\hline $\begin{array}{c}\text { Community and everyday life } \\
* \text { Degree of resolution }\end{array}$ & & & $-.130-.114$ \\
\hline $\begin{array}{c}\text { Family } \\
* \text { Degree of resolution }\end{array}$ & & & $.338 .275^{* *}$ \\
\hline $\begin{array}{c}\text { Economic } \\
* \text { Degree of resolution }\end{array}$ & & & $-.251^{-.241}$ \\
\hline $\begin{array}{c}\text { Psychological } \\
* \text { Degree of resolution }\end{array}$ & & & $.045 \quad .035$ \\
\hline $\begin{array}{c}\text { Physical } \\
* \text { Degree of resolution } \\
\end{array}$ & & & $-.032-.028$ \\
\hline$R^{2}$ & .398 & .521 & .553 \\
\hline$\triangle R^{2}$ & & .123 & .032 \\
\hline adj $R^{2}$ & .386 & .509 & .533 \\
\hline $\mathrm{F}$ & $33.551^{* * *}$ & $45.821^{* * *}$ & $27.896^{* * *}$ \\
\hline$\Delta_{\mathrm{F}}$ & & $64.940^{* * *}$ & $3.581^{* *}$ \\
\hline
\end{tabular}

$* p<.05, * * p<.01, * * * p<.001$
1단계에서 한부모가정 부모의 스트레스를 투 입하여, 경제적 스트레스와 신체적 스트레스는 생활만족도에 유의미한 영향을 미치는 것으로 나타났다. 2단계에서 스트레스 해소정도를 추가 로 투입한 결과 $R^{2}=0.521$ 로 설명력이 $52.1 \%$ 로 증가하였으며, 스트레스 해소정도, 경제적 스트 레스, 신체적 스트레스 순으로 생활만족도에 유 의미한 영향력을 미치는 것으로 나타났다. 3단계 에서 스트레스와 스트레스 해소정도와의 상호작 용을 추가로 투입하여 $R^{2}=0.553$ 으로 설명력이 $55.3 \%$ 로 증가하였으며, 스트레스 해소정도, 가족 스트레스와 스트레스 해소정도와의 상호작용, 경 제적 스트레스, 경제적 스트레스와 스트레스 해 소정도와의 상호작용, 신체적 스트레스 순으로 생활만족도에 유의미한 영향력을 미치는 것으로 나타났다.

\section{4 한부모 생활만족도 하위특성요인}

스트레스해소법에 따른 한부모가정 스트레스 와 생활만족도와의 관계를 파악하고자 상관분석 과 회귀분석을 실시하여 조절효과를 검증하였다. 이 특성의 하위요인을 재정적, 정서적, 인지적 요인으로 나누어 분석하였다.

\subsection{1 재정적요인 만족도}

한부모가정 부모의 스트레스가 재정적 요인 에 대한 만족도에 영향을 미칠 때 스트레스 해 소정도의 조절효과를 살펴본 결과는 Table 4.와 같다.

1단계에서 한부모가정 부모의 스트레스를 투 입하여, 경제적 스트레스와 신체적 스트레스는 재정적 요인에 대한 만족도에 유의미한 영향을 미치는 것으로 나타났다. 2단계에서 스트레스 해 소정도를 추가로 투입한 결과 $R^{2}=0.561$ 로 설명 력이 $56.1 \%$ 로 증가하였으며, 경제적 스트레스, 스트레스 해소정도, 신체적 스트레스 순으로 재 정적 요인에 대한 만족도에 유의미한 영향력을 미치는 것으로 나타났다. 3단계에서 스트레스와 
표 4. 재정적요인 만족도분석

Table 4. Analysis of financial satisfaction factors

\begin{tabular}{|c|c|c|c|c|}
\hline \multirow{3}{*}{ Division } & \multicolumn{4}{|c|}{$\begin{array}{l}\text { Dependent variable } \\
\text { :Financial factors }\end{array}$} \\
\hline & \multicolumn{2}{|c|}{ 1Step } & 2Step & 3Step \\
\hline & $\mathrm{B}$ & $\beta$ & $\beta$ & $\beta$ \\
\hline (Constant) & 5.145 & & 3.891 & $3.81 €$ \\
\hline $\begin{array}{c}\text { Community and everyday } \\
\text { life }\end{array}$ & -.004 & -.003 & $-.064-.05 \varepsilon$ & $-.08 c-.079$ \\
\hline Family & -.079 & -.074 & $-.032-.03 C$ & $-.01 \mathrm{c}-.018$ \\
\hline Economic & -.350 & $\begin{array}{l}-.38 \\
9^{* * *}\end{array}$ & $-.291 \frac{-.32}{3^{* * *}}$ & $-.311-.34$ \\
\hline Psychological & -.090 & $-.07 \varepsilon$ & $-.07 \varepsilon-.06 \varepsilon$ & $-.035-.034$ \\
\hline Physical & -.255 & $\begin{array}{l}-.24 \\
6^{* * *}\end{array}$ & $-.261 \frac{-.25}{2^{* * *}}$ & $-.257^{-}-.24$ \\
\hline Degree of stress & & & $.424 \quad .299$ & $.437 \stackrel{.309}{* * *}$ \\
\hline $\begin{array}{c}\text { Community and everyday life } \\
* \text { Degree of resolution }\end{array}$ & & & & $-.144-.089$ \\
\hline $\begin{array}{c}\text { Family } \\
* \text { Degree of resolution }\end{array}$ & & & & $.405^{.233}$ \\
\hline $\begin{array}{c}\text { Economic } \\
\text { * Degree of resolution }\end{array}$ & & & & $-.37 € \frac{-.25}{5 *}$ \\
\hline $\begin{array}{c}\text { Psychological } \\
* \text { Degree of resolution }\end{array}$ & & & & $.089 \quad .049$ \\
\hline $\begin{array}{c}\text { Physical } \\
* \text { Degree of resolution }\end{array}$ & & & & $-.04 c-.030$ \\
\hline$R^{2}$ & .477 & & .561 & .594 \\
\hline$\triangle R^{2}$ & & & .084 & .033 \\
\hline adj $R^{2}$ & .467 & & .551 & .576 \\
\hline $\mathrm{F}$ & 46.413 & & $53.905^{* * *}$ & $32.985^{* * *}$ \\
\hline$\Delta_{F}$ & & & $48.220^{* * *}$ & $4.020^{* *}$ \\
\hline
\end{tabular}

$\star \star p<.01, * \star \star p<.001$

스트레스 해소정도와의 상호작용을 추가로 투입 하여 $R^{2}=0.594$ 로 설명력이 $59.4 \%$ 로 증가하였 으며, 경제적 스트레스, 스트레스 해소정도, 경제 적 스트레스와 스트레스 해소정도와의 상호작용, 신체적 스트레스, 가족 스트레스와 스트레스 해 소정도와의 상호작용 순으로 재정적 요인에 대 한 만족도에 유의미한 영향력을 미치는 것으로 나타났다.

\subsection{2 정서적요인 만족도}

한부모가정 부모의 스트레스가 정서적 요인에 대한 만족도에 영향을 미칠 때 스트레스 해소정 도의 조절효과를 살펴본 결과는 Table 5.와 같다.

1 단계에서 한부모가정 부모의 스트레스를 투
입하여, 사회 및 일상생활 스트레스와 심리적 스 트레스는 정서적 요인에 대한 만족도에 유의미 한 영향을 미치는 것으로 나타났다. 2 단계에서 스트레스 해소정도를 추가로 투입한 결과 $R^{2}$ $=0.273$ 으로 설명력이 $27.3 \%$ 로 증가하였으며, 사 회 및 일상생활 스트레스, 스트레스 해소정도 심리적 스트레스 순으로 정서적 요인에 대한 만 족도에 유의미한 영향력을 미치는 것으로 나타 났다. 3단계에서 스트레스와 스트레스 해소정도 와의 상호작용을 추가로 투입하여 $R^{2}=0.291$ 로 설명력이 $29.1 \%$ 로 증가하였으나, 스트레스와 스 트레스 해소정도와의 상호작용은 유의수준 $5 \%$ 에서 정서적 요인에 대한 만족도에 유의미한 영 향을 미치지 않는 것으로 나타났다.

표 5. 정서적요인 만족도분석

Table 5. Emotional satisfaction factor analysis

\begin{tabular}{|c|c|c|c|c|c|c|c|}
\hline \multirow{3}{*}{\multicolumn{2}{|c|}{ Division }} & \multicolumn{6}{|c|}{$\begin{array}{l}\text { Dependent variable : Fmotional } \\
\text { factors }\end{array}$} \\
\hline & & \multicolumn{2}{|c|}{ 1Step } & \multicolumn{2}{|c|}{ 2Step } & \multicolumn{2}{|c|}{ 3Step } \\
\hline & & B & $\beta$ & B & $\beta$ & B & $\beta$ \\
\hline \multirow{7}{*}{ Stress } & (Constant) & 3.859 & & 2.99 & & 2.907 & \\
\hline & Community and everyday life & -.212 & -.234 & $-.22^{e}$ & $\begin{array}{l}-.2 \\
81^{* *}\end{array}$ & -.282 & $-.311^{*}$ \\
\hline & Family & -.001 & -.001 & .03 & .038 & .042 & .049 \\
\hline & Economic & -.070 & -.095 & $-.0<$ & $-.03 x$ & -.035 & -.048 \\
\hline & Psychological & -.204 & -.217 & -.16 & $\begin{array}{l}-.2 \\
08^{*}\end{array}$ & -.155 & -.165 \\
\hline & Physical & .028 & .033 & .02 & .028 & .014 & .017 \\
\hline & Degree of stress & & & .2 & 259 & .319 & $.277^{* * *}$ \\
\hline & $\begin{array}{l}\text { ommunity and everyday life } \\
* \text { Degree of resolution }\end{array}$ & & & & & -.192 & -.146 \\
\hline & $\begin{array}{c}\text { Family } \\
* \text { Degree of resolution }\end{array}$ & & & & & .224 & .158 \\
\hline & $\begin{array}{c}\text { Economic } \\
* \text { Degree of resolution }\end{array}$ & & & & & -.142 & -.118 \\
\hline & $\begin{array}{c}\text { Psychological } \\
* \text { Degree of resolution }\end{array}$ & & & & & .152 & .103 \\
\hline & $\begin{array}{c}\text { Physical } \\
* \text { Degree of resolution }\end{array}$ & & & & & -.099 & -.076 \\
\hline & $R^{2}$ & .211 & & & 73 & & 291 \\
\hline & $\Delta R^{2}$ & & & .0 & 63 & & 018 \\
\hline & adj $R^{2}$ & .195 & & & 56 & & 260 \\
\hline & $\mathrm{F}$ & 13.551 & & 15.8 & $43^{* * *}$ & & $66^{* * *}$ \\
\hline & $\Delta \mathrm{F}$ & & & 21.7 & $66^{* * * *}$ & & 272 \\
\hline
\end{tabular}

$* p<.05, * * p<.01, * * * p<.001$ 


\subsection{3 인지적요인 만족도}

한부모가정 부모의 스트레스가 인지적 요인 에 대한 만족도에 영향을 미칠 때 스트레스 해 소정도의 조절효과를 살펴본 결과는 Table 6.과 같다.

1 단계에서 한부모가정 부모의 스트레스를 투 입하였으나, 추정된 회귀모형은 유의수준 $5 \%$ 에 서 유의미하지 않았다. 2단계에서 스트레스 해소 정도를 추가로 투입한 결과 $R^{2}=0.089$ 로 설명력 이 $8.9 \%$ 로 증가하였으며, 스트레스 해소정도만 인지적 요인에 대한 만족도에 유의미한 영향력 을 미치는 것으로 나타났다. 3단계에서 스트레스 와 스트레스 해소정도와의 상호작용을 추가로 투입하여 $R^{2}=0.107$ 로 설명력이 $10.7 \%$ 로 증가 하였으나, 스트레스와 스트레스 해소정도와의 상 표 6. 인지적요인 만족도분석

Table 6. Factor analysis of cognitive satisfaction

\begin{tabular}{|c|c|c|c|}
\hline \multirow{3}{*}{ Division } & \multicolumn{3}{|c|}{$\begin{array}{l}\text { Dependent variable : } \\
\text { Cognitive factors }\end{array}$} \\
\hline & 1Step & 2Step & 3Step \\
\hline & B $\beta$ & B $\beta$ & $\beta$ \\
\hline (Constant) & 2.48 & 1.47 & 1.49 \\
\hline Community and everyday life & $.12 \vdots .121$ & $.08(.075$ & $.10<.098$ \\
\hline Family & $-.03-.038$ & $-.00-.001$ & $-.00-.001$ \\
\hline Economic & $-.14-.167$ & $-.09-.111$ & $-.10-.126$ \\
\hline Psychological & $-.04-.038$ & $-.03-.03 \mathrm{C}-$ & $-.04-.042$ \\
\hline Physical & $-.01-.012$ & $-.01-.017$ & .001 .001 \\
\hline Degree of stress & & .341 .253 & $.31 \underbrace{.236}$ \\
\hline $\begin{array}{c}\text { Community and everyday life } \\
* \text { Degree of resolution }\end{array}$ & & & $-.00-.005$ \\
\hline $\begin{array}{c}\text { Family } \\
* \text { Degree of resolution }\end{array}$ & & & $.37: \quad 227$ \\
\hline $\begin{array}{c}\text { Economic } \\
* \text { Degree of resolution }\end{array}$ & & & $-.16-.119$ \\
\hline $\begin{array}{c}\text { Psychological } \\
\text { * Degree of resolution }\end{array}$ & & & $-.20-.118$ \\
\hline $\begin{array}{c}\text { Physical } \\
\text { * Degree of resolution }\end{array}$ & & & $.10<.067$ \\
\hline$R^{2}$ & .030 & .089 & .107 \\
\hline$\Delta R^{2}$ & & .060 & .018 \\
\hline adj $R^{2}$ & .010 & .068 & .067 \\
\hline $\mathrm{F}$ & 1.548 & $4.134^{* *}$ & $2.702^{* *}$ \\
\hline$\Delta_{F}$ & & $16.591^{* * *}$ & .985 \\
\hline
\end{tabular}

$* * p<.01, * * \star p<.001$
호작용은 유의수준 $5 \%$ 에서 인지적 요인에 대한 만족도에 유의미한 영향을 미치지 않는 것으로 나타났다.

\section{IV. 논의 및 결론}

본 연구에서는 스트레스해소법에 따른 한부 모가정 부모의 스트레스와 생활만족도의 관계를 분석하였다. 연구의 결과를 토대로 논의하면 다 음과 같다.

첫째. 한부모의 인구사회학적 특성은 경제, 자녀양육 및 교육부담 그리고 편견과 복지혜택, 직장, 전배우자와의 관계 등이 생활만족도에 영 향을 미치고 있다. 결과는 인구사회학적 특성에 따라 한부모의 만족도에 차이가 있다는 것이다. 이 의미는 남희수[7]와 김은영[9]의 안정된 생활 유지 및 경제생활보장과 자립, 다양한복지욕구, 경제적 심각성이 상당부분 일치하고 있다.

둘째. 한부모의 스트레스는 경제, 신체, 사회 및 일상생활, 가족, 심리 순으로 높게 나타나고 유의미한 영향을 미친 것으로 나타났다. 결과는 스트레스에 따라 한부모의 스트레스증상에 차이 가 있다는 것이다. 이 의미는 호유연[6]과 남희 수[7]의 한부모 가정에서 스트레스에 영향을 미 치는 요인분석과 일정부분 일치한다.

셋째, 한부모의 스트레스해소정도에 따라 해 소정도, 경제, 신체 순으로 유의미한 영향을 미 치는 것으로 나타났다. 결과는 생활만족도가 해 소방법을 통하여 조절 및 향상되고 있는 것이다. 이 의미는 한부모의 이해 그리고 경제와 신체 및 편견을 중심으로, 해소법연구와 개발의 필요 성이 절실하다는 것과 같은 의미이다.

넷째. 스트레스와 생활만족도 관계는 재정적 은 스트레스, 스트레스해소, 스트레스와 스트레 스해소와의 상호작용에서 모두 만족도에 유의미 한 영향을 미치는 것으로 나타났다. 그리고 정서 적은 스트레스, 스트레스해소가 유의미한 영향력 을 미치는 것으로 나타났고, 인지적은 스트레스 해소만이 유의미한 영향력을 미치는 결과로 나 
왔다. 이 의미는 황은숙[2]의 한부모는 대부분 정서적으로 상실감, 실패감, 불안감, 좌절감, 분 노감, 우울감을 느끼며, 경제적 고충 속에서 자 녀를 양육하고, 이혼, 사별 등 변화된 가족체계 에 적응하지 못하고 있다고 밝히고 있는 것과 유사하다.

따라서 본 연구에 나타난 이 의미는 한부모 가정 부모의 스트레스와 스트레스해소법의 조절 효과가 유의미하게 작용함으로 인해 생활만족도 가 높아진다는 것을 파악할 수 있다.

이상의 연구결과를 토대로 다음과 같이 제언 하고자 한다. 첫째, 한부모의 경제와 신체 스트 레스가 높게 파악되고 있어 이 결과 향후 한부 모가정 지원 및 프로그램개발 대책과 개선이 시 급한 것으로 사료된다. 둘째, 한부모는 사회적 편견 및 일상생활, 경제적 어려움, 자녀양육의 부담 및 가족, 정서적 및 심리적 혼란, 신체적문 제 등의 스트레스는 해소법에 따라 생활만족도 에 영향을 미치고 향상되었다. 한부모의 생활만 족도 증진에 스트레스해소법이 유의미하게 작용 하므로, 지원정책수립과 프로그램개발에 기초자 료로 활용될 것으로 사료된다. 향후 한부모가정 부모와 스트레스해소법과 상관관계의 연구가 요 구된다.

\section{References}

[1] Other Do, mi-hyang, "Family jeongchaekron " shinjeong, p. 239, 2012.

[2] Hwang, eun-soog, "Study on the life condition ofsingle parent family and support expansion plan" Society of Single Parent Families, p. 60, 2012.

[3] Hwang, eun-soog, "Single-parent home, children's education" Love Korea times single parents, pp. 25-26, 2013.

[4] Country Indicators, 2010.

[5] Chung, dong-hwa, "Psychosocial stress" Korea Research Information Co, p. 11, 2010
[6] Ho, yu-yeon, "Single parents parenting stress and social support and the relationship ” Department of Child Studies, Kyungwon University Graduate School, 2008.

[7] Nam, hui-su, "The impact of economic stress and family function of a low-income household of single mother family on the quality of life" Christian Department of Social Welfare, Ph.D. Baekseok University Graduate School, 2010.

[8] Kim, oh-nam, "Single Mothers' and Adolescents' Family Stress and Psychological Well-Beiig" Department of Home Economics, Chonnam National University Graduate School Ph.D, 2010.

[9] Kim, eun-young, "A study on the characteristics of single-parent family" Department of Social Welfare, Pyeongtaek University Graduate School, 2003.

[10] Kim, Mi-Sook, "A Study on Support Services and Improvement Plans for Single-parent Families" Department of Social Welfare, Soongsil University Graduate School, 2010.

[11] Thomas Homes and Richard Rahe, '(SRRS : Social Readjustment Rating Scale), America.

[12] Cha, ese-oil, "Social Science Research Methods” Beopmunsa, p. 251, 1980. 


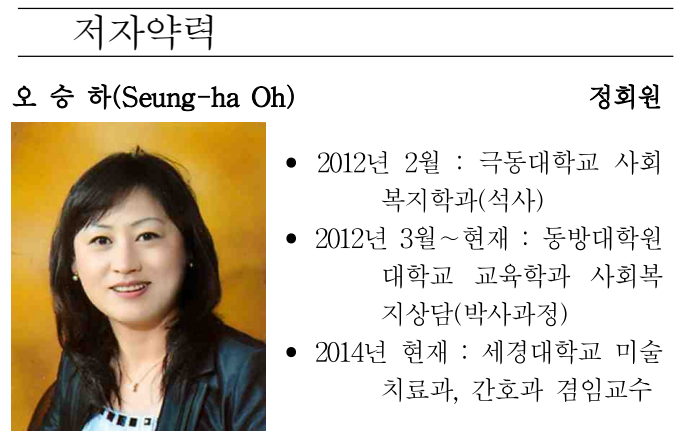

<관심분야> 한부모가정, 노인의 성, 노인상담

조 성 제(Sung-Je Cho)

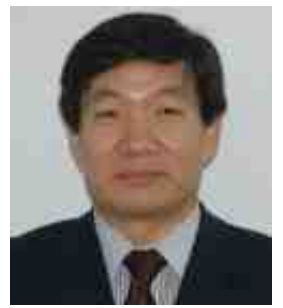

- 1977년 2월 : 홍익대학교 전자 계산학과(이학박사)

- 2007년 3월 현재 : 동방대학원 대학교 교육학과 교수

<관심분야> 문화콘텐츠 개발, 정보보안 